\title{
Framework for the Economic Analysis of Hybrid Systems Based on Exergy Consumption
}

The INL is a

U.S. Department of Energy

National Laboratory

operated by

Battelle Energy Alliance

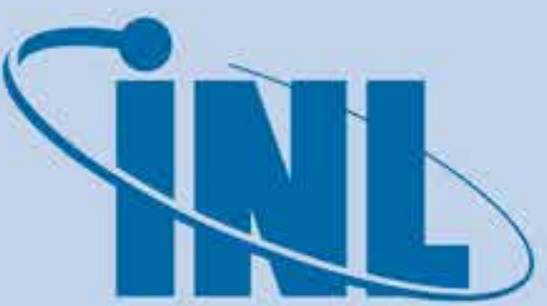

Idaho National Laboratory
Cristian Rabiti

Robert S. Cherry

Wesley R. Deason

Piyush Sabharwall

Shannon M. Bragg-Sitton

Richard D. Boardman

August 2014 



\title{
Framework for the Economic Analysis of Hybrid Systems Based on Exergy Consumption
}

Cristian Rabiti

Robert S. Cherry

Wesley R. Deason

Piyush Sabharwall

Shannon M. Bragg-Sitton

Richard D. Boardman

\author{
August 2014 \\ Idaho National Laboratory \\ Idaho Falls, Idaho 83415
}

http://www.inl.gov 


\begin{abstract}
Beginning with an overview of the evolving dynamic behavior of the electricity market, this report presents an approach to better inform energy users within that market to enable them to make sound decisions. These users are an essential component in providing a damping capability to the nationwide electric grid as the energy generation systems become more diverse and intermittent. This work includes a qualitative analysis of the impact of uncertainty, both in the demand and supply side. An introduction to investment analysis methodologies based on discounted cash flow is then provided, followed by an illustration and application of exergonomic principles to cost accounting of plant components used in cash flow analysis. Exergonomics is a new approach to the investment analysis of proposed systems, where the cost driver for product stream allocation is exergy utilization. Thus, through exergonomics, the opportunity cost generated due to incomplete usage of potential work (exergy), is minimized, or perhaps even eliminated.
\end{abstract}




\section{CONTENTS}

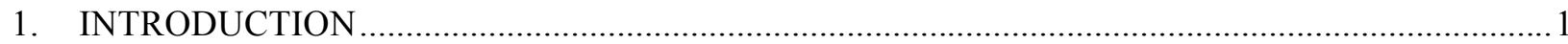

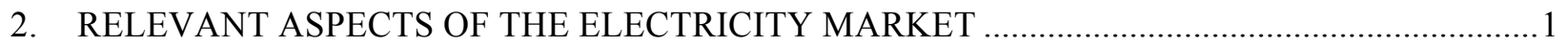

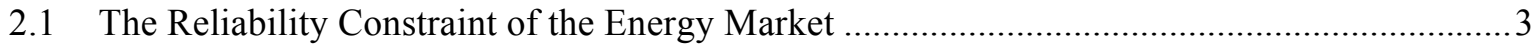

2.2 Additional Energy Users to Stabilize the System .....................................................................

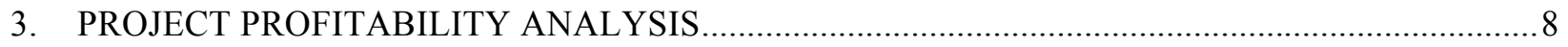

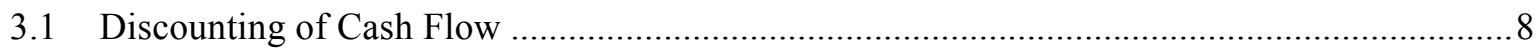

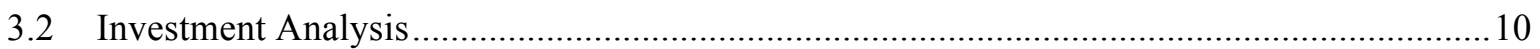

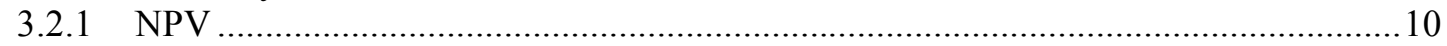

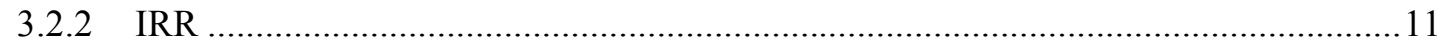

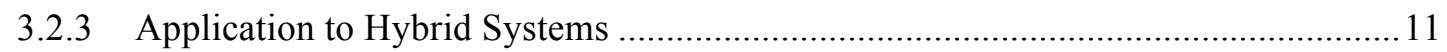

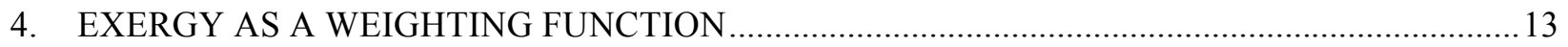

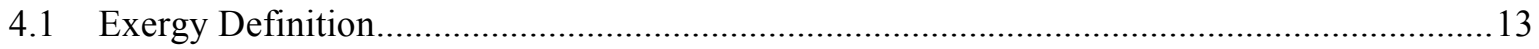

4.2 Exergy Usage as a Weighting Function for Cost Partitioning .............................................15

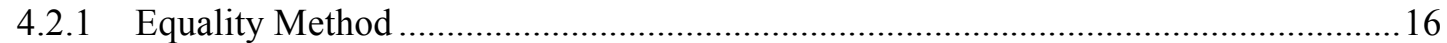

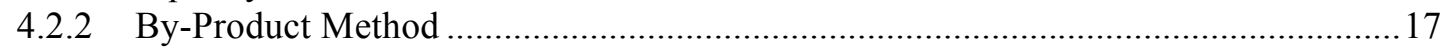

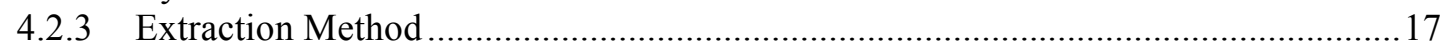

4.2.4 Comparison of Weighting Methods ……............................................................ 17

4.3 Concluding Remarks on Cost Allocation ........................................................................ 18

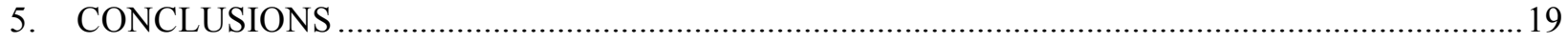

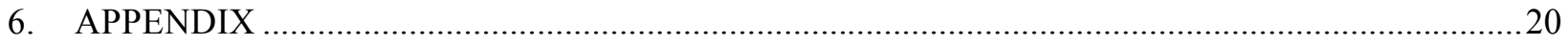

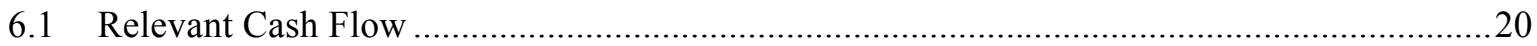

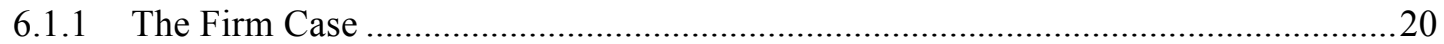

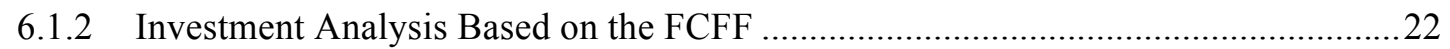

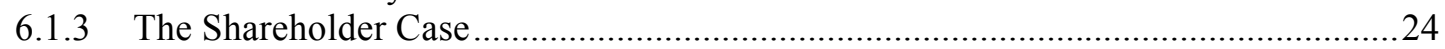

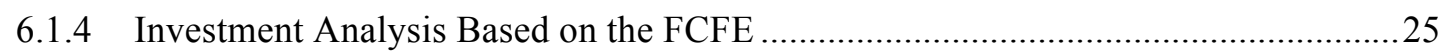

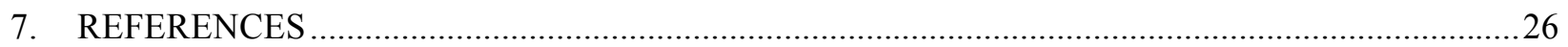




\section{FIGURES}

Figure 1. Qualitative Offer-Demand Wholesale Spot Energy Market. ........................................................2

Figure 2: Electricity Supply Stack for the Southeast Region of the U.S. (Source: U.S. Energy Information Administration, derived from Ventyx Energy Velocity and EIA Form-923 data, http://www.eia.gov/todayinenergy/detail.cfm?id=9090\#tabs_SpotPriceSlider-1) 3

Figure 3. Effect of Increased Volatility in the Supply Side. The marginal cost of electricity production in off peak production shifts to the left (from the blue to the purple curve). If this happens while there is a peak in the demand, there is a mismatch between grid capacity and demand, leading to potential blackout

Figure 4. Overlapping Demand and Supply Probability Distribution Functions. .......................................5

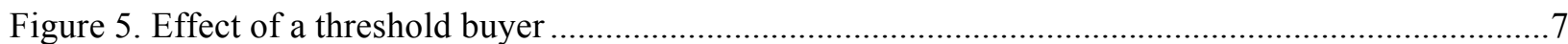

Figure 6: The electricity production is broken down into two subsystems. It is hypothesized that a third subsystem could be operating in parallel with respect to Subsystem 2. The figure highlights the flow of goods among the systems.

Figure 7: In this figure the flow of goods described in Figure 6 is replaced by the corresponding mutual cash flow. 8

Figure 8. Cogeneration Schematic. 


\section{TABLES}

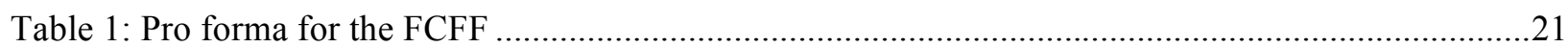

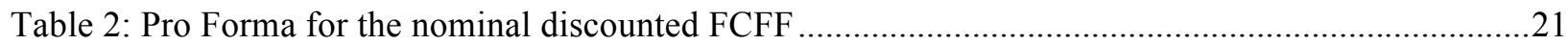

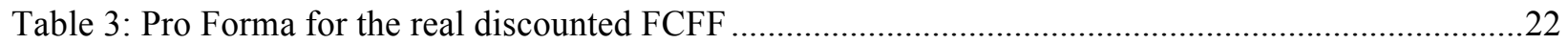

Table 4: Comparison between nominal and real discounted FCFF .......................................................22

Table 5: Comparison between nominal and real discounted FCFE......................................................25 


\section{Framework for the Economic Analysis of Hybrid Systems Based on Exergy Consumption}

\section{INTRODUCTION}

The increased deployment of variable renewable energy sources for electricity generation is challenging the current structure of the electricity market, weakening the competitive advantage that low energy prices represent for the U.S. In fact, while the low price of electricity has been a driver for the return of manufacturing industry from overseas in recent years (Celasun O., 2014), the long-term stability of such advantage could be compromised by the large addition of renewable energy sources. This situation is particularly evident for electricity sources characterized by very low variable cost and high volatility of supply such as solar and wind. As a result, dispatchable baseload electricity generators may be pushed out of the market because of short-term lack of economic viability. This situation and its dynamic evolution are depicted in Section 2. The best approach to reversing this trend, which could lead to either decreased reliability of the overall energy supply or to increased electricity prices, is not yet clear. Several options are currently being investigated. Despite the specific makeup of the final energy supply, it is reasonable to foresee that the optimal mix will not be achievable by a local optimization process (improving performance of each single component of the mix/grid), but rather by optimizing the performance of the overall system.

Optimization of such a complex system could be simplified by identifying the "response function" of isolated subsystems. Such an approach requires identifying "value" flow among the subsystems and value disruption within each subsystem in a manner in which the optimization reflects generation of value for the society. This problem has already been investigated to achieve optimization of complex thermodynamics processes and their corresponding parent industrial facilities (Bejan A., 1996). One of the most successful approaches in this direction is thermo-economics based on exergetic analysis (Valero A., 2006).

The work presented in this report is focused on demonstrating that this approach is suitable for the analysis of tightly integrated electricity supply systems. The proposed system would include nuclear energy and renewable energy generation, which could supply energy to heat users in addition to electricity to the grid (i.e., hybrid systems). The reasons behind selection of exergetic analysis for hybrid systems is explained in Section 4 after first introducing the fundamental basis of the classical economic evaluation of capital investment in Section 3.

\section{RELEVANT ASPECTS OF THE ELECTRICITY MARKET}

The goal of this section is to explain how and at what generation fraction the introduction of renewable electricity supply decreases the resilience of the electricity market, and to identify the characteristics that new system components should possess to mitigate this effect. The manufacturing industry is currently showing a renewed interest in relocating production to U.S. soil. One of the reasons for this return is attributed to lower, productivity-adjusted, labor costs and electricity costs in the U.S. (Celasun O., 2014). Unfortunately, as noted by others (DeVries et al. 2003), the stability of low electricity cost is dependent on a narrow balance between demand and offer, and this is due to the stiffness of the energy production system.

To better understand this phenomenon, it is necessary to look into the supply-demand dynamics of the energy market. First, the electricity market in the U.S. varies regionally depending on whether the region has a regulated or deregulated market. The regulated market structure is thought to control short-term oscillation present in the electricity market, ensuring a fair return to operators (electricity suppliers) and a fair price to consumers. The definition of "fairness" requires knowledge of what the average electricity price would be in a completely deregulated market. At this point, it is necessary to discuss the dynamic structure of a deregulated market to gain an overall picture of the electricity market. The simplest pricing 
strategy for a deregulated market is "local marginal pricing," where the "shadow price" (i.e. marginal cost, or the price that the cheapest supplier available would accept to dispatch an additional kilowatt-hour $[\mathrm{kWh}]$ in excess of the current demand) is computed at a specified time interval (usually one hour or half hour) and is paid to all the suppliers. To avoid to large swing in electricity price, local marginal pricing strategy is usually implemented through the use of edging mechanisms (intended to smooth price oscillations) and capacity rewards (e.g. a supplier "reward" for offering stand-by power to ensure supply security).

A classical supply and demand curve for the wholesale electricity market is shown in Figure 1. This figure illustrates the sharp rise in price (intersection of the supply-demand curve) when the demand peaks (e.g. daytime) relative to a low demand situation (e.g. night time). Figure 2 provides an example of a real electricity stack for the Southeast U.S. market.

Two important characteristics should be highlighted. First, Figure 1 demonstrates how the demand is practically inelastic (steep curve), while the supply curve suddenly shifts from being almost perfectly elastic (flat line) on the left side of the plot to almost perfectly inelastic as it approaches total installed capacity. The stiffness of the demand curve is true for both short and long-term time scales. This has generally been confirmed by statistical studies on the time evolution of electricity demand elasticity (Bernstein M. A., 2006). The explanation for this stiffness is simple; it results from the fact that residential users are not very sensitive to electricity price (due to lack of alternatives) and the relocation of industrial facilities involves large capital losses. Over the longer term some elasticity can be noted for industrial users, possibly due to relocation of production facilities and adoption of more energy efficient industrial processes.

The perfect inelasticity of the supply curve on the right side of Fig. 2 is due to the lead-time to dispatch other energy supply resources onto the grid. The almost complete elasticity of the curve on the left is due to the presence of suppliers with a cost structure characterized by high capital costs and low marginal costs that best fit constant demand. The transitional regime is dominated by production means having an opportunistic market approach, with low capital costs and high variable costs best suited to profit from the volatility of the demand.

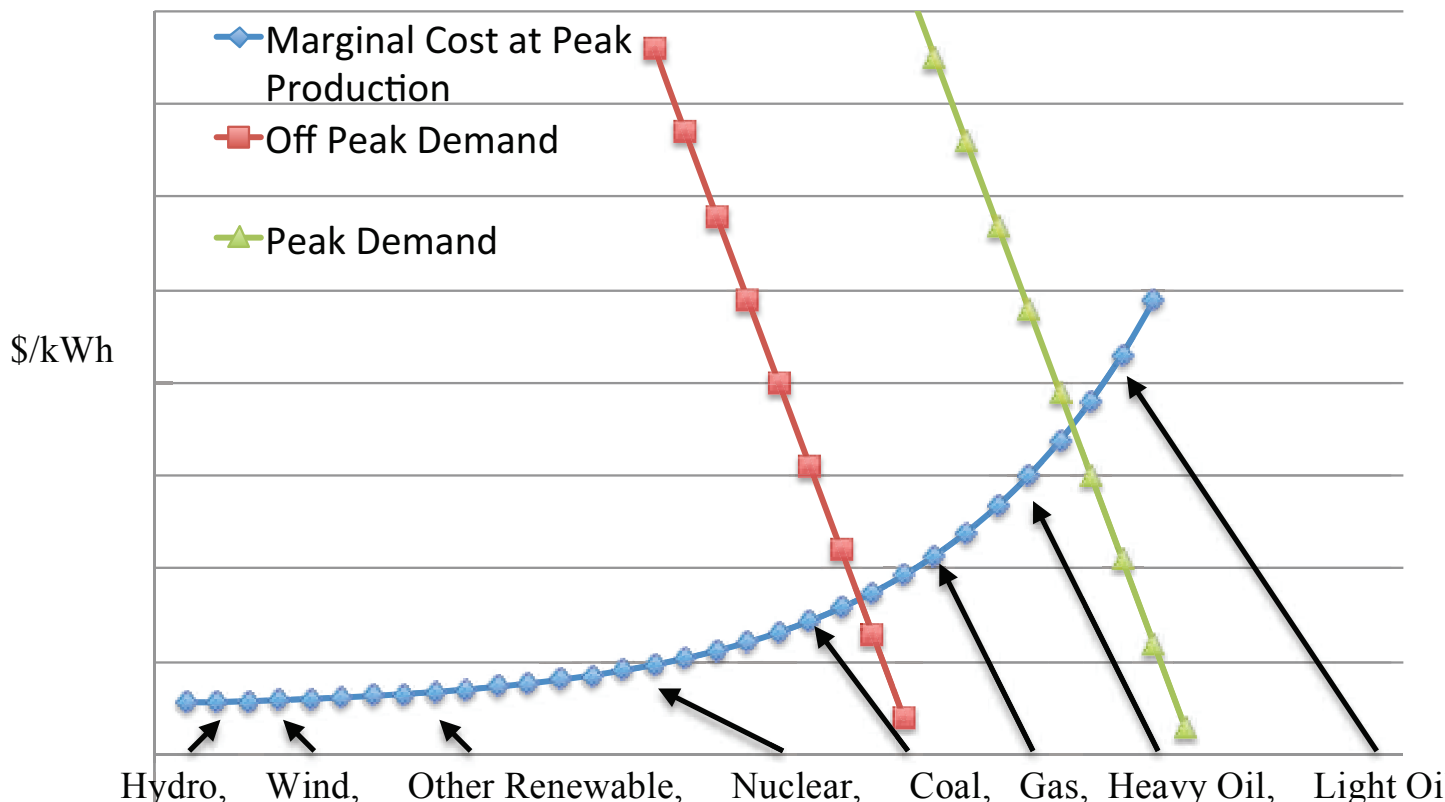

$\mathrm{kWh}$

Figure 1. Qualitative Offer-Demand Wholesale Spot Energy Market. 


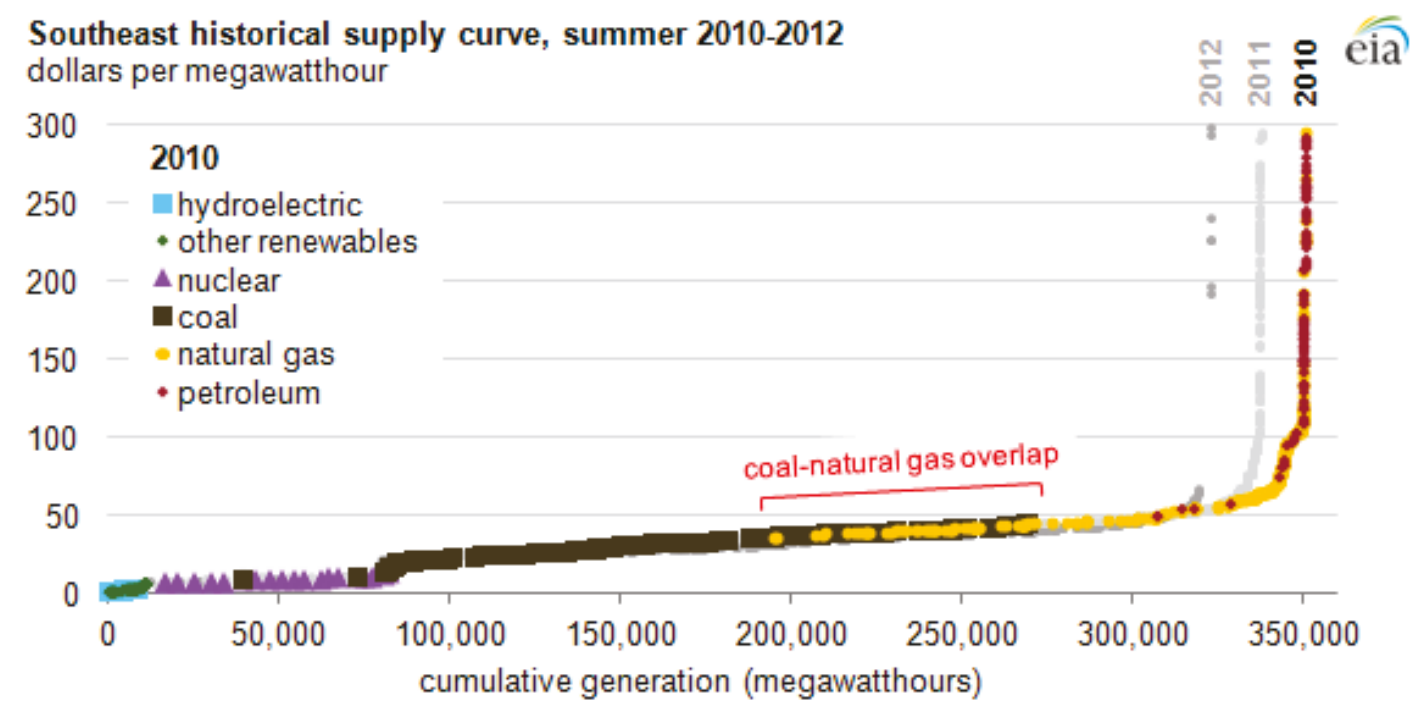

Figure 2: Electricity Supply Stack for the Southeast Region of the U.S. (Source: U.S. Energy Information Administration, derived from Ventyx Energy Velocity and EIA Form-923 data, http://www.eia.gov/todayinenergy/detail.cfm?id=9090\#tabs_SpotPriceSlider-1)

There are multiple consequences of this type of market elasticity structure. For example, a competitive energy price advantage only exists over a narrow range of demand, suddenly fading out when the demand increase approaches the installed capacity. In the long term, the offer curve could readjust to increased demand and this would shift the offer curve to the right. However, to avoid years of high electricity prices, an accurate long-term forecast of the electricity demand is needed. As a minimum, this forecast should be projected for the time required for construction of new capacity. In short-term situations, however, where the demand exceeds the available capacity, constraining the demand side can have significant consequences. In fact, the wholesale market has previously shown that, under the current structure, it is incapable of adjusting based on the opportunity cost of stopping productive activity (this is referred as value of lost energy or load, (Paul et al. 2006). The consequence is rolling blackouts as demand exceeds supply capacity. Smart meters that can automatically adjust the demand curve may increase the overall elasticity of the market, but, at this time, the benefit of smart meters remains unproven.

While agreement concerning how the energy market should be designed to be more efficient has not been reached among responsible authorities (DeVries et al. 2003), it is clear that higher demand volatility negatively influences investment in spare capacity to maintain reliability of the grid.

Finally, the addition of renewable power generation increases the volatility of the supply (or bid) for electricity. Given the grid is constrained by the need for a perfect match between supply and demand, 'must take' renewable energy is equivalent to increase in demand volatility.

\subsection{The Reliability Constraint of the Energy Market}

As was mentioned above, in terms of electricity price and reliability of the grid, supply volatility has the same effect as demand volatility. This section provides an example to illustrate such behavior and quantitative information to assess the magnitude of the impact of introducing an energy supply resource characterized by high volatility. One should note that electricity generation systems must be designed such that the electricity demand cannot exceed the available supply at any point in time - requiring design to meet peak demand and with contingency to address both intermittency and equipment failures.

Error! Reference source not found. shows qualitatively what can happen when both the supply and demand side have large volatility. When peak demand exceeds dispatchable capacity, a blackout can arise. The occurrence of a blackout is avoided by the introduction of reasonably probabilistic margins 
between the forecast peak demand and the available capacity. In particular, the North American Electric Reliability Corporation (NERC), the regulatory body that oversees the reliability of the North American electric grid, prescribes, as a guideline, that dispatchable capacity should exceed the forecast peak demand by $10-15 \%$, depending on the predominant means of production (e.g., hydroelectric, nuclear, wind) (North American Electric Reliability Corporation). This guideline ensures that failure of critical grid components during a period of peak demand will not lead to a blackout situation.

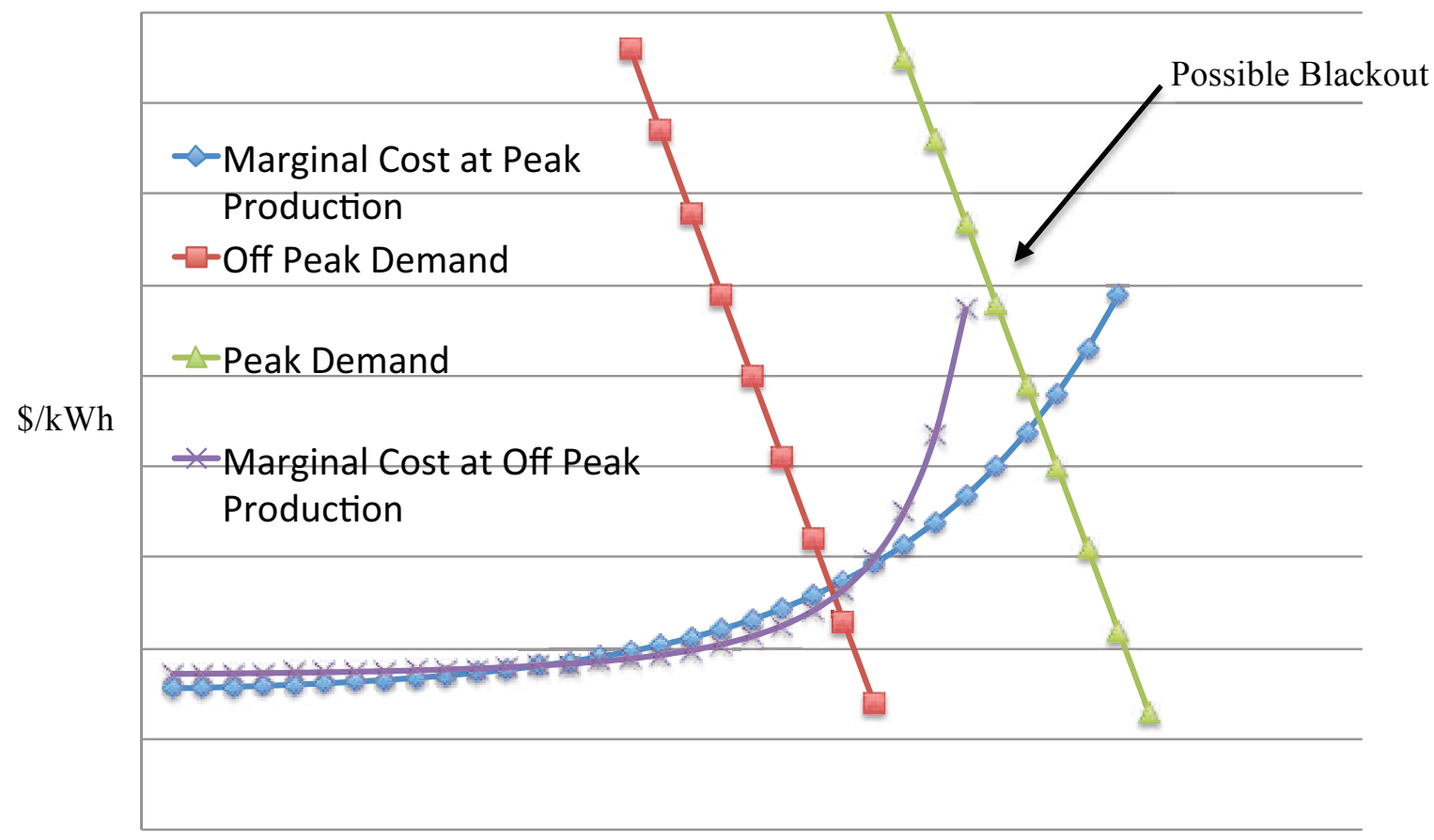

$\mathrm{kWh}$

Figure 3. Effect of Increased Volatility in the Supply Side. The marginal cost of electricity production in off peak production shifts to the left (from the blue to the purple curve). If this happens while there is a peak in the demand, there is a mismatch between grid capacity and demand, leading to potential blackout.

For highly volatile energy production means, such as wind, the capacity credit (i.e., the amount of installed conventional nominal capacity that could be eliminated for 100 units of new capacity installed) can be very low. For example, the average capacity credit recognized for wind generation by the Midcontinent Independent System Operator (MISO) was 13.3\% in 2013 (North American Electric Reliability Corporation, 2013). This implies that to cover a forecast peak demand of $1 \mathrm{GW}, 8.64 \mathrm{GW}$ of installed wind capacity is needed as computed here for $15 \%$ excess capacity:

$$
\text { Peak Demand*1.15= installed conventional capacity }
$$

$$
\text { Peak Demand*1.15/0.133=8.64 }
$$

Note: Photovoltaic generation usually receives a higher capacity credit (Madaeni S. H., 2012).

To qualitatively appreciate the impact to the installed capacity requirements that result from the combined volatility in the demand and offer curves, it is possible to run through a simple mathematical model of the problem. The no blackout condition, at any moment in time, could be formulated as:

$$
C-D>0 \text {, }
$$

where $C$ and $D$ are, respectively, the time dependent dispatchable capacity on the grid and electricity demand $([C]=[D]=$ Watts $)$. As both $C$ and $D$ are aleatory variables, this condition should be translated in probabilistic terms: 
where $T h$ is the non-blackout probability chosen by the regulatory body, and $C D F$ is the cumulative distribution function of the capacity minus demand.

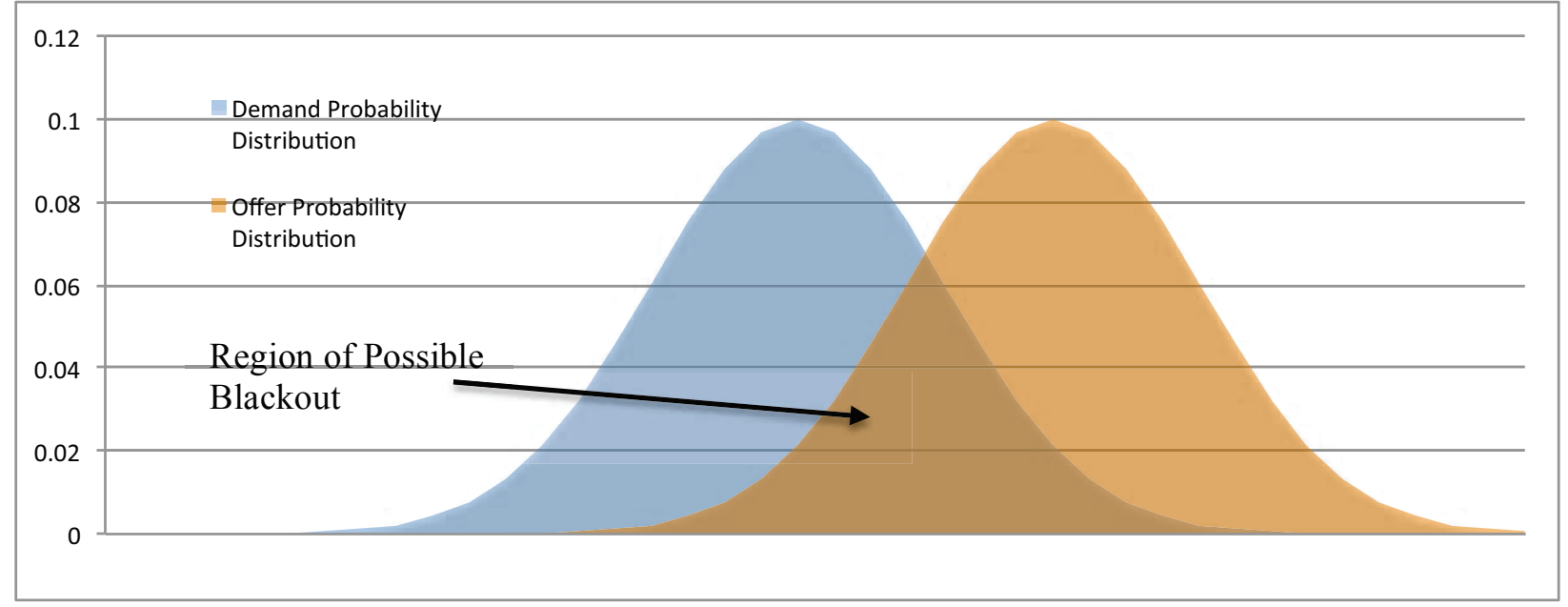

Figure 4. Overlapping Demand and Supply Probability Distribution Functions.

For example, Error! Reference source not found. shows two probability distribution functions (illustrative of demand and offer); the overlapping region would be the region of possible blackout. Under the simplifying assumption that both are normally distributed and not correlated, $\Delta=C-D$ is normally distributed with mean $\mu_{\Delta}=\mu_{C}-\mu_{D}$ and sigma $\sigma_{\Delta}=\sqrt{\sigma_{C}^{2}+\sigma_{D}^{2}}$. Now, the condition that the onset of a blackout situation has a chance of occurrence below a certain threshold (Th) can be expressed by:

$$
C D F(\Delta \geq 0)<T h .
$$

Once the value of $T h$ is set by reliability requirements, the above constraint can be expressed as a function of the mean and sigma of $\Delta$ (assuming the normal distribution assumption is valid). For example, setting $T h=1.27 \%$ (equivalent to a reliability of $98.73 \%$ ) leads to the following statistical relationships:

$$
\begin{gathered}
\mu_{\Delta}-3 \sigma_{\Delta}=\mu_{C}-\mu_{D}-3 \sqrt{\sigma_{C}^{2}+\sigma_{D}^{2}}<0 \\
\mu_{C}-\mu_{D}>3 \sqrt{\sigma_{C}^{2}+\sigma_{D}^{2}}
\end{gathered}
$$

It now becomes clear that the mean of the installed capacity should exceed the mean of the demand by a factor that is equally proportional to the variability of the demand and offer. Thus, an increase in the average value of the available capacity is independent from the source of the increased volatility. Moreover, if a certain amount of capacity is replaced on the grid by a supplier with higher volatility, observations thus far suggest that the new supplier will be required to have a higher nominal capacity. If 
the capital cost of the new supply is equal to the previous supply resource (per installed MW), then the overall average price of electricity will have to increase to cover the added capital costs.

From a private investor point of view, the capital recovery is computed using the availability factor of the plant. The asymptotic behavior of the overall market is quite different. In fact, to ensure the reliability of the grid, if we replace all supplier, the total needed installed capacity will be:

$$
C_{T}=D_{P}(1+\text { Request Excess Conventional Capacity }) / c c
$$

where $C_{T}$ is the total capacity, $D_{P}$ is the peak demand, and $c c$ is the average capacity credit of the grid. If all of the generation capacity were supplied by wind, for example, installation of roughly eight times the peak demand would be required. Given that the electricity sold over the plant operating lifetime will be equal to the mean demand, the utilization factor that should be considered for the capital cost recovery is:

$$
\text { CC } \frac{\mu_{D}}{D_{P}(1+\text { Request Excess Conventional Capacity })} .
$$

At the current stage of wind penetration the asymptotic situation is still far off, and given the low variable cost of wind generation, the utilization factor to be applied in the capital recovery calculation is still close to the physical availability of the wind. It is nonetheless important to look at the asymptotic values that will represent the long-term trends. The real computation of what is called the capacity credit is rather more complex. As an example, one could refer to Milligan et al. 2008.

The above discussion quantitatively illustrated how an increase in supply volatility results in an increase in both the mean and nominal value of the installed capacity. The next section addresses the characteristics that new system components should have in order to mitigate fragility of the electricity market.

\subsection{Additional Energy Users to Stabilize the System}

As illustrated in the previous discussion, the characteristics relevant to supplier electricity market dynamics are the ratio of capital to variable costs (which determines the ranking in the supplier stack) and the availability of the generation source (higher availability corresponds to low variability). At the same time, it was shown that reliability could be subtracted/added to the system from both the supply side and demand side equivalently. Moreover, the combination of the demand volatility and supply volatility could lead to a very high long-term price of electricity.

Given the above discussion, it is important to understand what the characteristics of additional energy suppliers should be to absorb the volatility of the market and how financial viability of these systems could be assessed. Assume, for example, a production process exists for which it would be profitable to buy energy of some form (thermal or electrical) up to a certain price; above that price, production would be put on hold. Another case could be a user for which energy input represents a major component of production or operation costs; if the product is sold on a very elastic market it would be natural to pass the volatility of the costs on to the market itself.

In both cases the addition of such processes would lead to a higher elasticity of the demand side (the first example would act more on a short time scale, while the second would likely apply to a seasonal timeframe). In fact, if we now look back to the demand-offer graph in terms of energy and we add, for example, a large user that would pull out of the market above a certain electricity price threshold, it would lead to the market dynamic in Figure 5, far reducing the energy price spike of the peak demand. This scenario would, in practice, translate to a reduction in the difference between the mean demand and the peak demand, implying lower spare capacity installed in the system. 


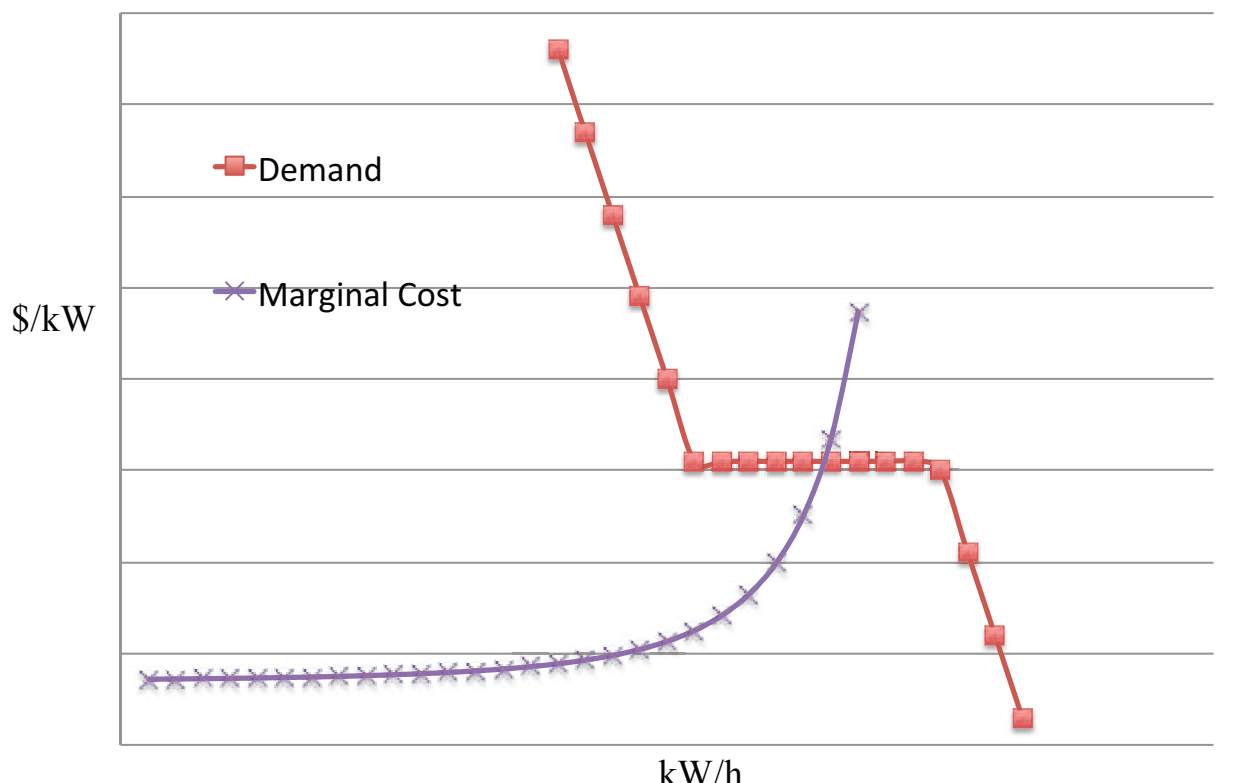

Figure 5. Effect of a Threshold Buyer.

The expression "energy user" has purposely been used to imply the possibility of both electricity and direct (thermal) energy users. In reality, if an electricity-price-dependent, variable process using only electricity exists, its existence would have been already reflected by a larger elasticity of the market.

The system considered to study possible candidates for introducing a damping/stabilizing effect in the energy grid is illustrated in Figure 6. The electricity production is broken down into two subsystems and it is hypothesized that a third subsystem could be operating in parallel with respect to Subsystem 2.

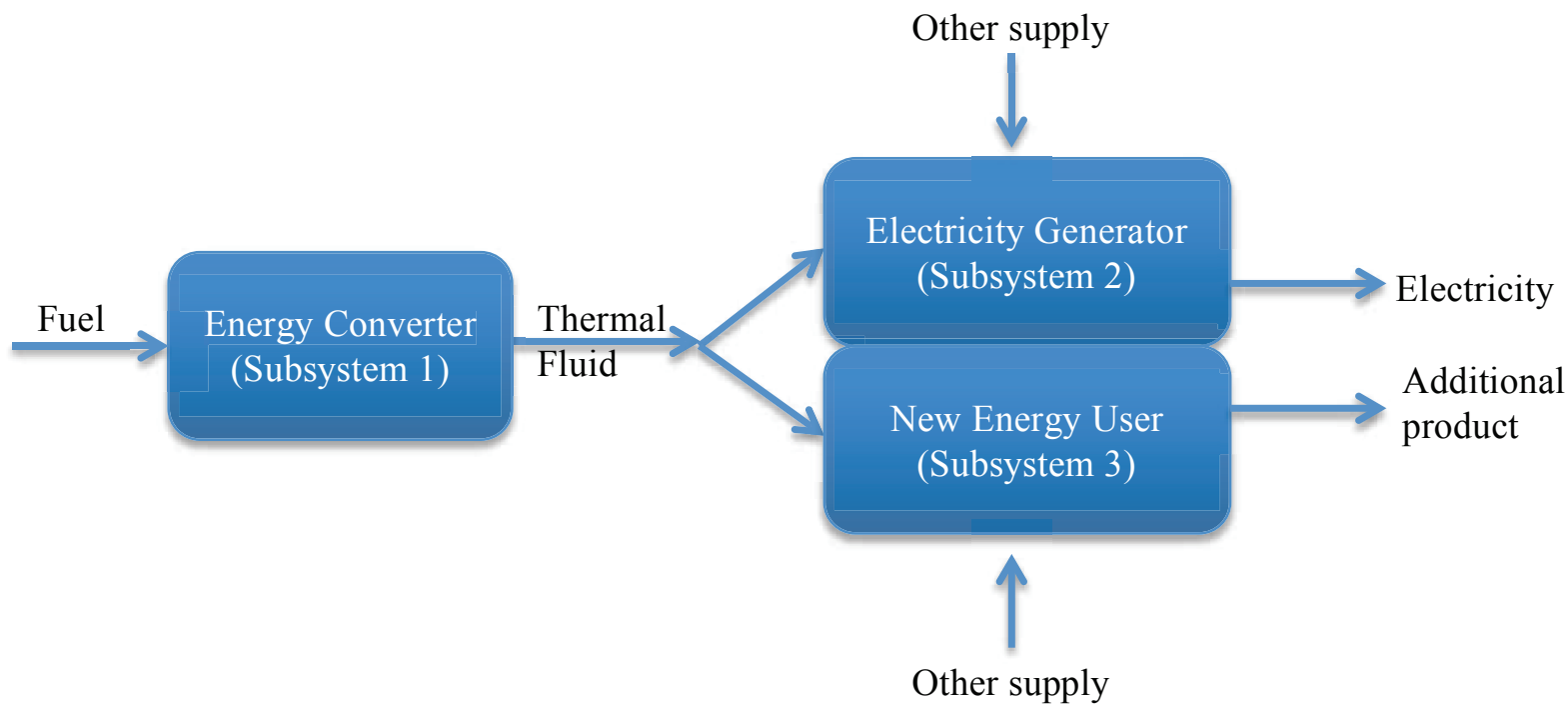

Figure 6: The electricity production is broken down into two subsystems. It is hypothesized that a third subsystem could be operating in parallel with respect to Subsystem 2. The figure highlights the flow of goods among the systems.

In addition and in parallel to the exchange of the generic energy supply for each block of the system there will be an exchange of funds. This flow of money should be in balance with the capital costs (where 
the capital costs might or might not account for the investor profit, as explained in the next section) and with the operations and maintenance $\left(\mathrm{O} \& \mathrm{M}^{*}\right)$ costs ("O\&M" costs usually include the acquisition of the thermal fluid input, whereas the "O\&M*" costs reference here usually include this cost):

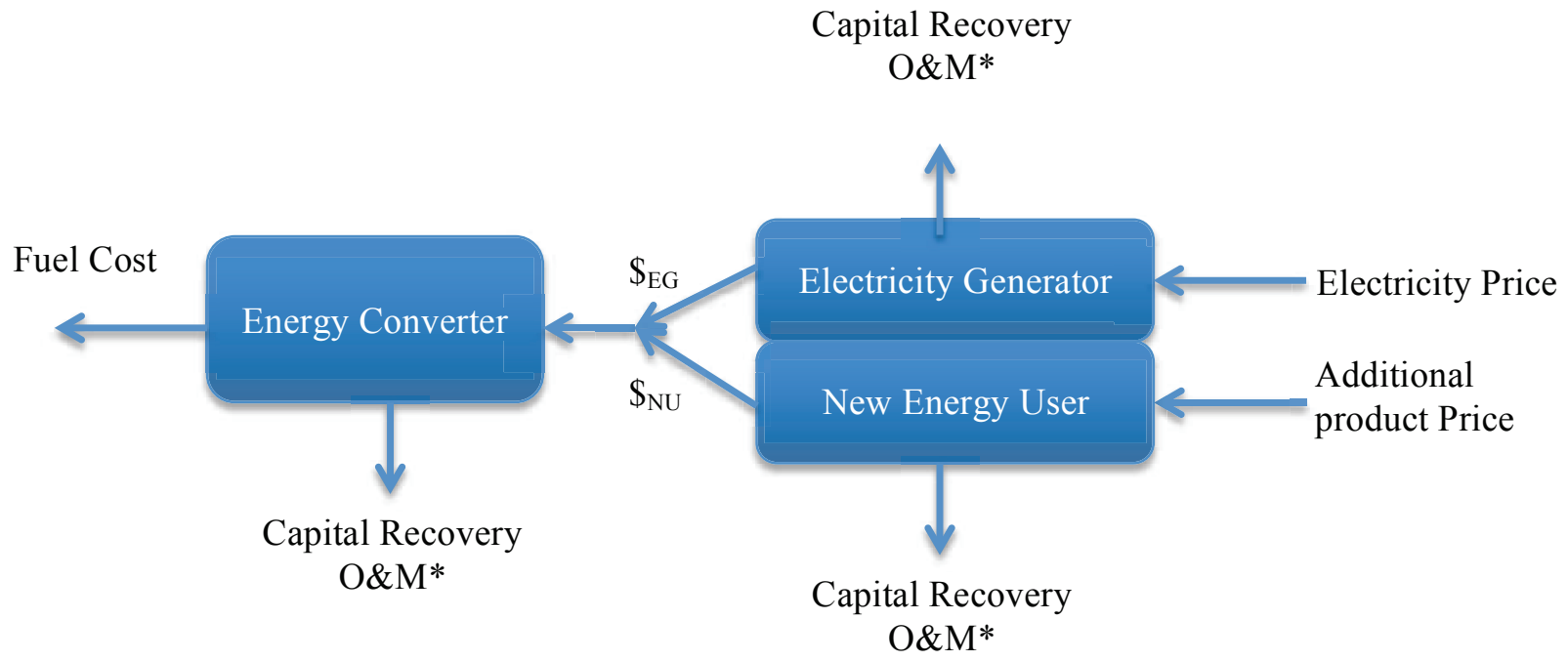

Figure 7: The flow of goods described in Figure 6 is replaced by the corresponding mutual cash flow.

As will be explained in the following section from the market condition, it is possible to determine the necessary value of $\$_{\mathrm{EG}}+\$_{\mathrm{NU}}$, respectively, the sum of the cash flow from Subsystems 2 (Electricity Generator) and 3 (New Energy User) to Subsystem 1, but the ratio of $\$_{\mathrm{EG}} / \$_{\mathrm{NU}}$ is currently unknown. While this ratio is not necessary to establish the financial balance of the whole system it is necessary to establish the profitability of each individual subsystem. The profitability of each subsystem is a crucial point for the financial feasibility of the project as it is possible that multiple entities will own/finance each individual subsystem. The objective is to provide a system of congruent equations to allow all the cash flow in the above diagram to be determined.

\section{PROJECT PROFITABILITY ANALYSIS}

The goal of this section is to identify how the cash balance of each system component should be used to assess the financial feasibility analysis of the project.

\subsection{Discounting of Cash Flow}

The financial analysis of a proposed project is often based on a prediction of its cash flow, as this is a tangible quantity less subject to manipulations with respect other accounting quantities. In addition, at the end of the project, it will be equivalent to the overall profit or loss. To begin the explanation, it is necessary to introduce some definitions:

Present worth: The worth at the present time of an amount of money owned at another point in time.

Future worth: The worth of an amount of money after a period of time.

Discounting: Obtaining the present worth of a future amount of money.

Cash flow: Tangible yearly cash balance. In simple cases, income to the company from product sales minus expenses due to taxes and operational costs (raw materials, salaries, maintenance, etc.). 
Inflation rate: The percentage loss of purchasing power of a certain amount of money on a yearly basis.

Rate of return: The percentage rate at which an investor expects his or her money to provide profit relative to the size of the investment.

Discount rate: The interest rate used across time to reduce the value of future dollars to today's dollars.

Discount factor: The factor that is multiplied by a future amount of money to determine its present worth; derived using the discount rate.

The first quantity that needs to be explained is the discount factor. The discount factor is the coefficient that allows computation of the real worth of a certain amount of worth generated in the future or in the past with respect to the reference time. In the scope of the financial analysis for the current project, a discrete analysis will be used. Thus, the discount factor described in Eq. 6 is based on a yearly average and is called the discrete discount factor. In addition, the discount factor derived below does not include discounting due to inflation such that it is the nominal discount factor ( $\mathrm{N}$ subscript). The assumptions below are generally applied in discrete cash flow analysis:

- The years are counted from the beginning of the project, i.e., the first year goes from $\mathrm{T}=0$ to $\mathrm{T}=1$ year.

- Cash flow will occur in discrete values; in this case, once a year.

- Cash flow concerns only the revenues and expenses for a specific project, not the company as a whole.

Given these assumption and common convention, the nominal discrete discount factor for year $y\left(d_{y, N}\right)$ is given by:

$$
d_{y, N}=\frac{1}{\left(1+r_{N}\right)^{y}}
$$

where $r_{N}$ is the nominal rate of return. The discount rate can be taken as a factor used to weigh present cost versus future revenue. The discount factor can then be applied to the cash flow of the project for each year to determine the present worth of the total cash flow over the lifetime of the project.

For

- $C F_{N, y}$ : net nominal cash flow seen during the year $y$,

- $\quad D C F$ : Discounted Cash Flow,

$$
D C F=\sum_{y=0}^{N} d_{y, N} C F_{N, y}=\sum_{y=0}^{N} \frac{C F_{N, y}}{\left(1+r_{N}\right)^{y}}
$$

Because most cash flows that comprise the $C F_{N, y}$ will evolve over time following inflation, it is useful (and actually less prone to uncertainty propagation) to sterilize the process from the impact of inflation.

The above consideration allows for a direct formulation of $r_{R}$, the real rate of return: 


$$
\frac{1}{\left(1+r_{R}\right)^{y}}=\frac{(1+i)^{y}}{\left(1+r_{N}\right)^{y}}
$$

One can also derive the real rate of return directly by imposing the assumption that a cash flow that grows with the inflation rate appears as a constant contribution over time.

$$
C F_{N, y}=\left(C F_{0}\right)(1+i)^{y}
$$

It is also possible to prove that, on first order approximation, the real rate of return is the nominal rate of return minus the inflation rate.

$$
r_{R}=\frac{\left(1+r_{N}\right)}{(1+i)}-1=\frac{r_{N}-i}{(1+i)} \cong\left(r_{N}-i\right)\left[1-i+O\left(i^{2}\right)\right]=r_{N}-i+O\left(i^{2}\right)
$$

By introducing the definition of the real cash flow at year $y\left(C F_{R, y}\right)$ the $D C F$ is equal at:

$$
\begin{gathered}
C F_{R, y}=\frac{C F_{N, y}}{(1+i)^{y}} \\
D C F=\sum_{y=0}^{N} \frac{C F_{N, y}}{\left(1+r_{N}\right)^{y}}=\sum_{y=0}^{N} \frac{C F_{R, y}}{\left(1+r_{R}\right)^{y}}
\end{gathered}
$$

\subsection{Investment Analysis}

Long-term investment decisions and the most relevant figures of merit for investment analysis are based on Net Present Value (NPV) and Internal Rate of Return (IRR). NPV and IRR are complementary indicators of investment profitability.

NPV: The present worth of all the inflows and outflows of cash in a project using an assumed discount rate.

IRR: The discount rate for which the NPV is equal to zero; in other words, the rate of return that the project will generate.

Discussion on which of the indicators is most meaningful can be found in many financial management books (Higgins, 2009); but, generally speaking, it largely depends on the boundary conditions of the problem (e.g., constrained resources, mutually exclusive projects). A general overview of how they are computed is provided below.

\subsubsection{NPV}

Steps to compute NPV:

1. List the revenues and expenses for each year over the project lifetime.

2. Compute the discount factor using the proper rate of return.

3. Find the present worth of revenues and expenses using an assumed discount rate.

- $\quad \mathrm{NPV}>0$ : the project produces cash in excess of the required return on the investment 
- $\quad \mathrm{NPV}<0$ : the project does not produce cash in excess of the required return on the investment

The main drawback of this approach is that it requires knowledge of the discount factor. For a firm, the Weighted Average Cost of Capital (WACC) is often used to compute the correct discount factor.

\subsubsection{IRR}

Steps to compute IRR:

1. List the revenues and expenses for each year over the project lifetime.

2. Solve one of the equations below (depending on whether the nominal [Eq. (8)] or real [Eq. (9)] IRR is sought):

$$
\begin{aligned}
& \sum_{y=0}^{N} \frac{C F_{N, y}}{\left(1+I R R_{N}\right)^{y}}=0 \\
& \sum_{y=0}^{N} \frac{C F_{R, y}}{\left(1+I R R_{R}\right)^{y}}=0
\end{aligned}
$$

The IRR can be made useful to a firm or individual by comparing it to their hurdle rate $(H R)$. A hurdle rate is a firm's or individual's minimum IRR (which could be the WACC or another number chosen by the company). A proper hurdle rate can be determined by comparing it with the return offered by the company investment portfolio.

- $I R R_{N / R}>H R$ : the project return exceeds the return accepted by the investor

- $I R R_{N / R}<H R$ : the project return does not exceed the return accepted by the investor

\subsubsection{Application to Hybrid Systems}

In essence, the IRR and the NPV are the most used figures of merit to evaluate the economic viability of capital expenditure projects. Both figures are based on the knowledge of the relevant cash flow. The NPV also requires knowledge of the discount rate, while the IRR uses it only as a reference point. Unfortunately, the effectiveness of the IRR is limited by the fact that it does not allow for changes in the discount rate that could be used to reflect changes in the project risk over the lifetime of the infrastructure. The use of the NPV versus the IRR is more widely discussed in Appendix A, which also discusses how to define the relevant cash flow in relationship with the choice of the proper rate of return.

The cash flow is a necessary piece of information regardless of whether IRR or NPV is the preferred figure of merit. The case of the free cash flow will presently be examined (from the company point of view) since the difference between the equity cash flow and the free cash flow is mostly independent from the financial structure of the company and is not impacted by the independent ownership of integrated subsystems.

Prior to starting the profitability analysis for each system component we first need to establish if the system will act as "price taker" or "price maker." Depending on this choice the degrees of freedom of the problem will be different:

Price Taker: This model is the most classical for financial investment analysis. By using the market price, the model allows one to establish cash flow toward capital recovery, which is where the investors collect profit. The advantage of this model is that it does not require any assumption on the profit required by the investors to establish the cash flow.

Price Maker: In the case where there is a monopoly (either created by legislation or de facto) the supplier is capable of deciding the price at which the product will be sold. In this case, the supplier acts as 
price maker with respect the market. The present work is focused on and will be influenced by future energy policy. Hence, it is reasonable to assume that, given a fair return to the investor, the market could be constrained to accept the cost of production that results from choices that are not driven completely by economic factors (e.g., reduced $\mathrm{CO}_{2}$ emissions could be a significant driver).

In the context of the current work, referring to Figure 7, the "Electricity Generator" should be a price maker because the analysis is looking to the overall electricity market. The "New Energy User" should be a price taker because output of this system is not thought to dominate the reference market.

Still looking to Figure 7, it is possible to write the cash balance equations (firm point of view):

$$
C R_{E C}=\$_{E G}+\$_{N U}-O \& M^{*}-F C \quad \text { Energy Converter }
$$

$C R_{E G}=-\$_{E G}+$ Electricity Cost $-O \& M^{*} \quad$ Electricity Generator $\quad$ Eq. 15

$C R_{N U}=-\$_{E G}+$ Additional Product Price $-O \& M^{*} \quad$ New Energy User

For simplicity, we start by replacing the following terminology:

$$
\begin{gathered}
\text { Electricity Cost } \rightarrow \text { Revenue }=R_{E G} \\
\text { Additional Product Price } \rightarrow \text { Revenue }=R_{N U}
\end{gathered}
$$

The system of equations Eq. 15 could therefore be reformulated as:

$$
\begin{array}{ll}
C R_{E C}=\$_{E G}+\$_{N U}-O \& M^{*}-F C & \text { Energy Converter } \\
C R_{E G}=-\$_{E G}+R_{E G}-O \& M_{E G}^{*} & \text { Electricity Generator }
\end{array}
$$

Now, rearrange the equation so that all unknowns are on the left and all known variables on the right. In doing so the following considerations are used:

- $\quad R_{N U}$ is, for the moment, a fixed value since the "New Energy User" is a price taker

- $R_{E G}$ is a variable since the "electricity produced" is a price maker

- $O \& M_{E G}^{*}, O \& M_{N U}^{*}, C R_{E G}$ are fixed values

- $C R_{N U}$ is a variable since we need to establish the possible profit for the "new energy user"

- $O \& M^{*}$ are operation and maintenance costs that exclude the acquisition of the thermal power; this is assumed to be a known constant

- $\$_{E G}, \$_{N U}$ are also unknown while $\$=\$_{E G}+\$_{N U}$ is known and can be added to the system of equations

$\begin{array}{lll}C R_{E C}-\$_{E G}-\$_{N U}=-O \& M^{*}-F C & \text { Energy Converter } \\ C R_{E G}+\$_{E G}=R_{E G}-O \& M_{E G}^{*} & \text { Electricity Generator } \\ C R_{N U}+\$_{E G}=R_{N U}-O \& M_{N U}^{*} & \text { New Energy User } & \text { Eq. 17 } \\ \$_{E G}+\$_{N U}=\$ & \text { Balance of the flow of thermal energy }\end{array}$

The system has five unknowns but only four equations. A second equation that relates $\$_{E G}+\$_{N U}$ is missing. This is a classical problem in joint product pricing or by-product pricing. In reality, neither byproduct nor joint product seems to offer a plausible way to repartition the cost between the different users. The approach that it is taken here is to repartition the cost among the different downstream users based on the potential work they take advantage of. As it will be shown in the next section, this is equivalent to splitting cost based on the exergy usage. 


\section{EXERGY AS A WEIGHTING FUNCTION}

The goal of the following sections is to introduce the concept of exergy, explain why it is the right figure of merit for understating the resource consumption of each subsystem in Figure 6, and explain why exergy is the proper cost driver for identification of production costs.

\subsection{Exergy Definition}

The term exergy was introduced for the first time by Rant et al. (1956), since then, several different definitions have attempted to capture the concept of exergy:

"Exergy is the amount of work obtainable when some matter is brought to a state of thermodynamic equilibrium with the common components of its surrounding nature by means of reversible processes, involving interaction only with the above mentioned components of nature." (Szargut et al. 1980)

Basically, exergy represents the maximum work that could be extracted from a system, given a fixed set of boundary conditions defining the surrounding environment. It is important to notice that the exergy is a state function of a system plus its environment.

Exergy was first defined for thermo mechanical systems, but it can be extended to account for any form of energy that could be used to generate work. While it is not the aim of this report to provide the expression of exergy for different types of systems, it is useful to provide some example concerning of how such estimation could be achieved.

From the above definition of exergy $(B)$ this basic relation follows:

$$
B=W_{\text {Ideal }}
$$

where $W_{\text {Ideal }}$ is the maximum work that the system could transmit toward the environment (this analysis adopts the convention that the work available from the system to the environment is positive).

For heat systems the maximum work that could be extracted is bounded by the ideal Carnot cycle; therefore, the temperature-based exergy $B_{T}$ is given by:

$$
B_{T}=Q\left(1-\frac{T_{0}}{T}\right)
$$

While this is a very limiting situation, it is immediately clear that $B$ tends to capture the heat $(Q)$ quality by introducing a quality factor related to the temperature of the system. In Eq. $19 T_{0}$ is the surrounding (environment) temperature. As expected from the definition of exergy, its mathematical expression should account for the status of the surrounding environment, usually referred to by the expression "Stable Reference Environment" (SRE). The variables that need to be defined to characterize the SRE are those that are needed to establish the maximum work that could be extracted.

For thermal systems the typical SRE variables are temperature and pressure $\left(T_{0}, p_{0}\right)$ or other conserved quantities that provide the same level of information, such as the enthalpy and entropy $\left(H_{0}, S_{0}\right)$ in the system at the corresponding state condition $\left(T_{0}, p_{0}\right)$. With respect to exergy, the standard conditions are usually defined as $T_{0}=298.15, P_{0}=1 \mathrm{~atm}$. For those systems the exergy could be defined as:

$$
B_{T h}=H-T_{0} S
$$

where $H$ and $S$ are, respectively, the enthalpy and entropy functions. There are many other characteristics that define the amount of work that could be extracted from a system. Hence, many other contributions to the total exergy have been defined: 
Mechanical $\quad B_{M}=\frac{M V^{2}}{2}+g z$

Electricity $\quad B_{E}=W_{e}$

Solar $\quad \dot{B}_{S}=\sigma T^{4}\left(1-\frac{4}{3} \frac{T_{0}}{T_{S}}+\frac{1}{3} \frac{T_{0}^{4}}{T_{S}^{4}}\right)$

where:

$M$ : Mass of the system

$V$ : velocity of the system

$g$ : gravitational constant

$z$ : elevation

$\sigma:$ Stefan-Boltzmann constant

$T_{S}$ : solar temperature

The definition of the mechanical exergy and electrical exergy relies on the fact that both forms of electrical and mechanical energy have a theoretical efficiency of one, while this is not true for the solar energy. It should be noted that there is not complete agreement on the exergy to be assigned to the solar radiation. In Neri et al. (2013) an overview of several possible approaches is presented.

The definition of the chemical exergy has been left out thus far since it requires further discussion before being properly introduced. One of the most challenging tasks in defining the chemical exergy is the definition of the SRE. The SRE should not only be defined in terms of temperature and pressure but also in terms of chemical species and their molar concentration. Generally the SRE is chosen to be one of the following (Querol E., 2013):

- Atmosphere. Saturated humid air, in equilibrium with liquid water. Provides reference substances: oxygen, nitrogen, as well as the other gases that make up the air including $\mathrm{CO}_{2}$, which is the reference substance for carbon.

- Hydrosphere. Saturated liquid water $\left(\mathrm{H}_{2} \mathrm{O}\right)$, which is a reference substance for hydrogen.

- Lithosphere. The reference substances are selected from those most abundant and of lowest value, existing in the solid crust.

For a truly stable SRE condition, the maximum chemical work that could be extracted from our system would be equal to the minimum work necessary to generate the chemical compound starting from the elements present in the SRE. Given high reaction threshold, it happens that some of the components present in the SRE have not reached the stable state. In this case it is possible that the work that could be extracted from the chemical compound (exergy content) could be greater than the work that is needed to create it from the components present in the reference status.

Using the minimum work approach (from the reactants in the SRE to the compounds in the system) three steps can be identified that require work. In fact, since the reactants will be mixed in the SRE, the creation of the system compounds requires: 1) de-mixing, 2) chemical reaction leading to the desired compound, and 3) the change of the thermodynamic coordinates from the SRE to the system coordinates. The first step could be accounted for by the introduction of a $B_{T h}$ component. The second step is 
evaluated by the introduction of the chemical potential of the species $i\left(\mu_{i, r}\right)$ in the SRE. The third step is accounted for by introduction of the free energy of formation. If the system is composed of several compounds it will be necessary to additionally account for the chemical potential of the mixture of the compounds. A detailed treatment of the exergy computation for mixtures of chemical compounds is beyond the scope of this report, but it is important to once more notice that the exergy accounts for all means of producing work. For example, if the system is composed of pure $\mathrm{CO}_{2}$ at the same pressure and temperature as the SRE, using the standard atmosphere defined for the SRE, the low partial pressure of $\mathrm{CO}_{2}$ in the SRE system will create the opportunity for work generation. This is properly accounted for by the chemical potential of $\mathrm{CO}_{2}$ in the SRE.

\subsection{Exergy Usage as a Weighting Function for Cost Partitioning}

This section highlights why and how we can begin from a simple situation that is representative of the difficulty in properly partitioning cost between $\$_{E G}+\$_{N U}$ (see Eq. 17). Figure 8 represents a cogeneration system. The proper way to partition the costs of steam generation, turbine capital costs, and operations and maintenance costs between electricity production and heat production is discussed.

When trying to allocate cost between different lines of production or, more generally, seeking to evaluate the costs associated with the generation of any type of product, the most natural answer is to associate the cost of the resources used for the generation of each product. More recently, these simple considerations have provided the basis for approaches such as Active-Based Costing and Resource-Based Costing (Eldenburg, Leslie G. \& Wolcott, 2005). The challenge faced in the current study is that the resources are not equally distributed between the different products. In the cogeneration example energy production uses steam at the quality exiting the boiler while the heat product benefits from a much lower steam quality. If energy usage out of the steam would partition the costs between the electricity generator (EG) and the new user (NU), the result will not be representative of the amount of work the electricity or the heat users have available to them.

Theoretically, it is possible to spend a certain amount of work (by each of the two final users) to generate from the SRE the necessary amount of steam. The sum of this work should equal the exergy content of the steam exiting the boiler. This demonstrates that exergy could be considered as the common denominator to define resource usage.

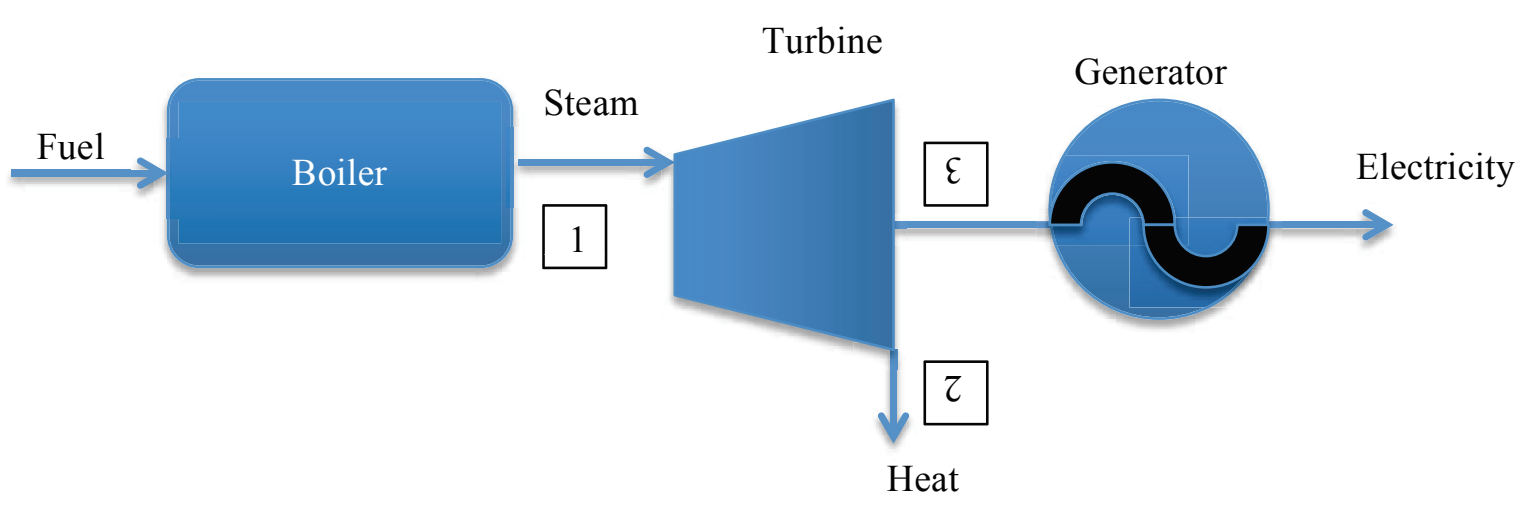

Figure 8. Cogeneration Schematic

To begin establishing the relationship between cost accounting and exergy flow it is necessary to introduce the following quantities (the is used to indicate the time derivative):

$\dot{B}_{i}$ : exergy flow at point $\mathrm{i}$

$\dot{B}_{i}^{*}$ : exergy flow used to generate the exergy content in the i-th stream $\dot{B}_{i}$ 
$c_{i}$ : exergy unit cost at point $\mathrm{i}$

$C_{i}$ : exergy cost at point $\mathrm{i}$

$Z=\frac{\text { Capital Recovery }+O \& M^{*}}{\text { Operational Period }}:$ component related costs

From these quantities it is possible to determine the cost balance for each system component located between stage $i-1$ and $I$ :

$$
c_{i-1} \dot{B}_{i-1}+Z=c_{i} \dot{B}_{i}
$$

If $i$ - 1 is considered the point of entry of the fuel ( $F$ subscript) and $i$ the point of exit of the product ( $P$ subscript), then:

$$
c_{F} \dot{B}_{F}+Z=c_{P} \dot{B}_{P}=C_{P}
$$

More generally, for each component of the system, this becomes:

$$
\sum_{i \in \text { in }} c_{i} \dot{B}_{i}+Z=\sum_{j \in \text { out }} c_{j} \dot{B}_{j}
$$

Eq. 26 reveals that the cost of exergy can only increase while a transformation occurs in a given component. The source of the cost increase is the presence of the component-related costs $Z$ and the exergy destruction $\sum_{i \in \text { in }} c_{i} \dot{E}_{i}-\sum_{j \in \text { out }} c_{j} \dot{E}_{j}$. Note that in this convention the cost of the product is only related to its exergy content since capital costs and O\&M are already part of the evaluation of the exergy cost. In this way the capital costs are embedded in the cost of exergy and the exergy is the only quantity that is exchanged in the system.

Once it is established that exergy usage represents a better cost driver of energy, one might wonder if the exergy exiting the turbine should be priced differently depending on the user. Some examples and conclusions from the work presented in Valero et al. (2009) are provided in this report. First, with reference to Figure 8, the cost balance equation could be written as:

$$
c_{1} \dot{B}_{1}+Z_{\text {turbine }}=c_{2} \dot{B}_{2}+c_{3} \dot{B}_{3}
$$

As in classical cost accounting, we consider several options in the following sections.

\subsubsection{Equality Method}

The most natural methodology is to evaluate both products equally, $c_{2}=c_{3}$. In this case the costs are split based on the exergy used:

$$
\begin{gathered}
c_{1} \dot{B}_{1}+Z_{\text {turbine }}=c_{2} \dot{B}_{2}+c_{3} \dot{B}_{3} \\
c_{2}=c_{3}=\frac{c_{1} \dot{B}_{1}+Z_{\text {turbine }}}{\dot{B}_{2}+\dot{B}_{3}}
\end{gathered}
$$




\subsubsection{By-Product Method}

Given the assumption that the primary goal is to generate electricity, and that usage of the excess or "waste" heat has no impact on the electricity production, we can assume:

$$
\begin{gathered}
c_{2}=0 \\
c_{3}=\frac{c_{1} \dot{B}_{1}+Z_{\text {turbine }}}{\dot{B}_{3}}
\end{gathered}
$$

\subsubsection{Extraction Method}

If we assume that the turbine's only purpose is to generate shaft power then there is no increase in the cost of exergy provided at the point 2 because all irreversibility costs and the component-related costs should be charged toward the shaft power production. In other words, this is equivalent to stating that the heat usage does not benefit from the presence of the turbine; therefore, it should not bear any of the associated costs. The partitioning of the costs is thus given by:

$$
\begin{gathered}
c_{2}=c_{1} \\
c_{3}=\frac{c_{1}\left(\dot{B}_{1}-\dot{B}_{2}\right)+Z_{\text {turbine }}}{\dot{B}_{3}}
\end{gathered}
$$

\subsubsection{Comparison of Weighting Methods}

To illustrate the difference between the results of these three methods, the cost of heat and electricity as co-products was calculated for an arbitrary set of costs and operating conditions. An input heat stream of $1000 \mathrm{MW}$ at a constant $550{ }^{\circ} \mathrm{C}$ was used for all cases. Exergy values were calculated using $25^{\circ} \mathrm{C}$ and 1 atm as the reference temperature and pressure. To calculate the relative heat versus electricity production, a real power cycle efficiency was approximated by using $75 \%$ of the ideal Carnot value for each case's conditions. In those cases, the heat stream from the turbine was presumed to be sold in its entirety to a heat-using process at some temperature determined by the process needs. This temperature was used as the low end heat-rejection temperature for the Carnot efficiency calculation. For economic inputs, the turbine capital recovery plus O\&M costs $(Z)$ were set at $\$ 5000$ per hour and cost of the input exergy was set at $\$ 10$ per MWh.
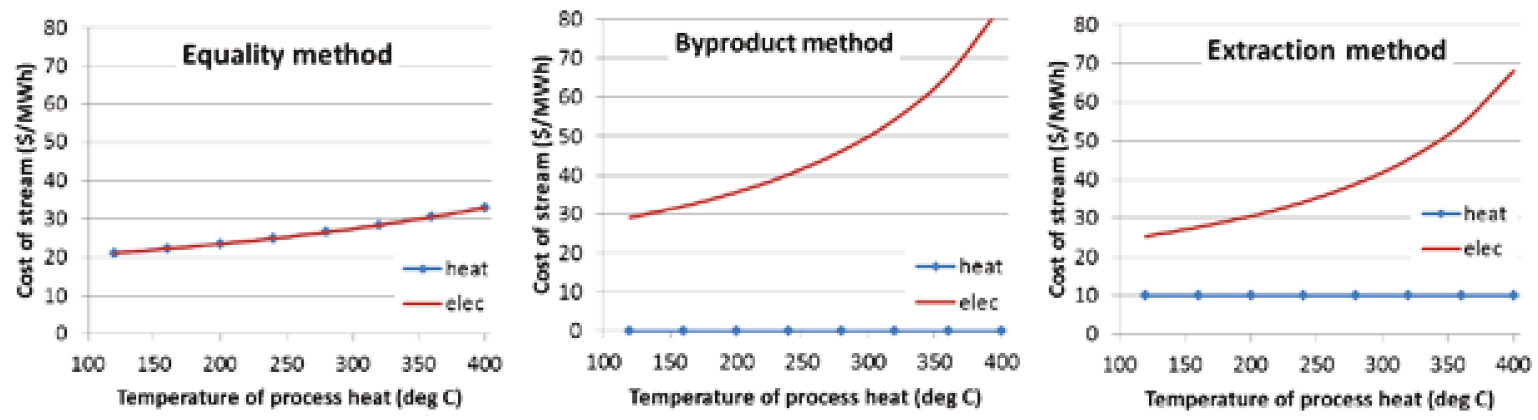

Figure 9. Comparison of alternative methods of pricing heat and electricity as co-products.

Figure 9 shows the results of this comparison. Using the equality method the cost curves for heat and electricity are identical, overlying one another on the graph. The costs increase with the process heat 
temperature because at higher rejection temperatures less work can be extracted by the power cycle from the constant amount of heat input. This in turn requires that more energy flow to the process plant at some temperature lower than the input temperature. This drop in temperature causes exergy destruction. With greater flows of the lower-exergy heat stream, the system costs are spread over less product exergy, requiring the unit cost of that product exergy to be higher.

The byproduct method has zero cost for the heat because it is assumed to be a worthless byproduct that can generate no revenue and, therefore, cannot bear any of the operating costs. The electricity cost is correspondingly the highest among all these cases because it must carry all of the operating costs. The extraction method assumes that the exergy in the heat product costs the same as the input exergy, and all other costs are allocated to electricity production. Its results are intermediate between the other two cases. Taken as a whole, these results show that the appropriate cost of each product stream can vary by a factor of two or more depending on the operating intent and operating conditions of the overall power cycle.

Qualitatively similar results are obtained if similar calculations are done for the cost of energy rather than exergy. This type of analysis can be extended even further to determine how other costs or benefits are to be split between co-products. One example of particular interest would be credits for reducing $\mathrm{CO}_{2}$ and other greenhouse gas emissions. The reference case might be taken to be a large modern coal-fired power plant. A natural gas-fired plant or a nuclear reactor could produce the same amount of electricity and heat for export to an external process but with lower $\mathrm{CO}_{2}$ emissions. This reduction would be the input stream that is to be divided between the two products using any of the methods described in this section.

\subsection{Concluding Remarks on Cost Allocation}

The methodologies described above are classical accounting procedures. When applied using exergy as a cost driver, they are equivalent to an allocation driven from the loss of potential work needed for the specific actions. This could be restated as follows:

- Equality method. Exergy dissipation cost is distributed following exergy usage.

- Extraction method. Exergy dissipation is borne by the electricity production.

- By-product method. The exergy content of the steam supplied to the heat production is considered waste; therefore, this approach increases the dissipation that is borne by the electricity production.

In conclusion, Eq. 27, Eq. 28, and Eq. 29 provide the closure needed to solve the system in Eq. 17. This solution allows for a cost accounting based on exergy flows, where the cost sources are the resources needed to construct and maintain the plant, and the exergy destruction. This approach allows for a direct identification of the contribution of energy degradation to manufacturing costs.

Finally, this analysis could eventually be extended to account for dynamic reallocation of resources between system components. Since accounting is usually performed on a yearly basis, it is important to see how the cash balance equation would be applied on a yearly basis.

$$
\int_{o}^{T}\left(\sum_{i \in \text { in }} c_{i}(t) \dot{B}_{i}(t)+Z(t)\right) d t=\int_{o}^{T}\left(\sum_{j \in \text { out }} c_{j}(t) \dot{B}_{j}(t)\right) d t
$$

$$
\text { Since } \int_{o}^{T}\left(\sum_{j \in \text { out }} c_{j}(t) \dot{B}_{j}(t)\right) d t=\text { Capital Recovery }+O \& M^{*}
$$

$$
\text { Capital Recovery }+O \& M^{*}=\int_{o}^{T}\left[\left(\sum_{j \in \text { out }} c_{j}(t) \dot{B}_{j}(t)\right)-\left(\sum_{i \in \text { in }} c_{i}(t) \dot{B}_{i}(t)\right)\right] d t
$$




\section{CONCLUSIONS}

In section 2 this report highlighted how the reliability constraint of the grid translates into an inverse relationship between installed capacity and volatility of supply. The same effect arises if either the supply or the demand side introduces volatility. The increasing penetration of renewable sources will result in increasing volatility on the supply side that must be damped to avoid disruption of the energy market. In the framework of hybrid, integrated systems this dampening is provided by thermodynamic systems capable of either passing the fluctuation in supply price to the final customer or to internally damp such oscillations. It will be necessary to perform the economical analysis of the global system including all components. This type of analysis is not trivial and requires a mapping between the exchange of thermal fluids and cash flow. This structure/framework is offered by a set of rules capable of translating all the possible quantities exchanged among the component of the system into exergy. The exergy framework presented here allows for construction of a representation of the global system as an exergy market, providing a representation that can be used for cost accounting and the economic evaluation of the plant. 


\section{APPENDIX}

\subsection{Relevant Cash Flow}

As seen in the section 3, one of the keys to financial evaluation of a project is knowledge of the proper discount factor and the cash flow. As will be shown in the following section, the right discount factor is tightly coupled to the definition of the proper cash flow. A different level of default protection (bondholder vs shareholders) determines a different risk exposure; therefore, it will require a different choice of the discount factor. Generally it is preferred to work in terms of real discount factor since many of the cash flows source are affected by inflation. The real discount factor can be defined with respect to the following two entities:

- The Firm (bondholders plus shareholders)

- The Shareholders

\subsubsection{The Firm Case}

In essence, the point of view of the firm relates to the shareholders point of view as the return on assets (ROA) relates to the return on equity (ROE).

The cash flow to the company is the cash flow available to pay back debt and equity and is usually called Free Cash Flow to Firm (FCFF).

The direct approach to the yearly $F C F F_{y}$ is:

$$
F C F F_{y}=\left(R_{y}-O \& M_{y}-D A_{y}\right)\left(1-\operatorname{tax}_{y}\right)+D A_{y}-\Delta W C_{y}-C A P E X_{y}
$$

Where:

$R_{y}:$ revenue from sales

$O \& M_{y}$ : operations and maintenance

$i$ : inflation rate

$\operatorname{tax}_{y}:$ tax rate

$D A_{y}$ : depreciation, Amortization (fixed depreciation amount as per the tables)

$\Delta W C_{y}$ : change in Working Capital

$C A P E X_{y}$ : Capital Expenditure

$\mathrm{SV}$ : salvage value

In the financial management word it is often introduced the Earning Before Interest Tax and Amortization EBITA:

$$
R_{y}-O \& M_{y}=E B I T A
$$

as also the Earning Before Interest Tax (EBIT):

$$
R_{y}-O \& M_{y}-D A_{y}=E B I T A-D A_{y}=E B I T
$$

In order to derive the FCFF it is useful to use a pro forma analysis of the cash flow that is depicted in Table 1. 
Table 1: Pro forma for the FCFF

\begin{tabular}{|c|ccccc} 
Year & 0 & $1, \ldots$ & $\ldots, \mathrm{A}^{*}$ & $\mathrm{~A}+1$ & $\mathrm{~N}^{* *}$ \\
$\boldsymbol{R}_{\boldsymbol{y}}$ & 0 & $R_{1}$ & $R_{A}$ & $R_{A+1}$ & $R_{N}$ \\
$\boldsymbol{O} \& \boldsymbol{M}_{\boldsymbol{y}}$ & 0 & $O \& M_{1}$ & $O \& M_{A}$ & $O \& M_{A+1}$ & $O \& M_{N}$ \\
$\boldsymbol{D} \boldsymbol{A}_{\boldsymbol{y}}$ & 0 & $D A_{1}$ & $D A_{A}$ & 0 & 0 \\
$\Delta \boldsymbol{W} \boldsymbol{C}_{\boldsymbol{y}}$ & 0 & 0 & 0 & 0 & 0 \\
$\boldsymbol{C A P E}_{\boldsymbol{y}}$ & $C$ & 0 & 0 & 0 & $S V$ \\
$\boldsymbol{F C F F}_{\boldsymbol{y}}$ & $-C$ & $\left(R_{1}-O \& M_{1}-D A_{1}\right)$ & $\left(R_{A}-O \& M_{A}-D A_{A}\right)$ & $\left(R_{A+1}-O \& M_{A+1}\right)$ & $\left(R_{N}-O \& M_{N}\right)$ \\
& & $(1-\operatorname{tax})+D A_{1}$ & $(1-\operatorname{tax})+D A_{A}$ & $(1-\operatorname{tax})$ & $(1-\operatorname{tax})+S V$
\end{tabular}

*A: number of years of amortization of the project

**N: total lifetime of the project

The cash flows considered thus far are in nominal values. Two terms entering in the cash flow analysis might show an evolution that follow the inflationary evolution pattern:

$$
\begin{gathered}
R_{y}=R_{o}(1+i)^{y} \\
O \& M_{y}=O \& M_{0}(1+i)^{y}
\end{gathered}
$$

The two above expressions are replaced in the pro forma analysis reported in Table 1. The result is reported in Table 2, while Table 3 reports the pro forma cash flow in real terms. The summary of the references are reported in Table 4.

\begin{tabular}{|c|c|c|c|c|c|}
\hline Year & 0 & $1, \ldots$ & $\ldots, \mathrm{A}^{*}$ & $\mathrm{~A}^{*+1}$ & $\mathrm{~N}^{* *}$ \\
\hline$R_{N, y}$ & 0 & $R_{o}(1+i)$ & $R_{o}(1+i)^{A}$ & $R_{o}(1+i)^{A+1}$ & $R_{o}(1+i)^{N}$ \\
\hline$o \& M_{N, y}$ & 0 & $O \& M_{0}(1+i)$ & $O \& M_{0}(1+i)^{A}$ & $O \& M_{0}(1+i)^{A+1}$ & $O \& M_{0}(1+i)^{N}$ \\
\hline$D A_{N, y}$ & 0 & $D A_{1}$ & $D A_{A}$ & 0 & 0 \\
\hline $\operatorname{CAPEX}_{N, y}$ & C & 0 & 0 & 0 & $S V$ \\
\hline$F C F F_{N, y}$ & $-C$ & $\begin{array}{l}\left(R_{o}(1+i)\right. \\
\left.-O \& M_{0}(1+i)-D A_{1}\right) \\
\quad(1-\operatorname{tax})+D A_{1}\end{array}$ & $\begin{array}{l}\left(R_{o}(1+i)^{A}\right. \\
\left.-O \& M_{0}(1+i)^{A}-D A_{A}\right) \\
\quad(1-\operatorname{tax})+D A_{A}\end{array}$ & $\begin{array}{l}\left(R_{o}(1+i)^{A+1}\right. \\
\left.-O \& M_{0}(1+i)^{A+1}\right) \\
\quad\left(1-\operatorname{tax}_{y}\right)\end{array}$ & $\begin{array}{l}\left(R_{o}(1+i)^{N}\right. \\
\left.-O \& M_{0}(1+i)^{N}\right) \\
\left(1-\operatorname{tax}_{y}\right)+S V\end{array}$ \\
\hline
\end{tabular}

Table 2: Pro Forma for the nominal discounted FCFF

*A: number of years of amortization of the project

$* * \mathrm{~N}$ : total lifetime of the project 
Table 3: Pro Forma for the real discounted FCFF

\begin{tabular}{|c|ccccc} 
Year & 0 & $1, \ldots$ & $\ldots, \mathrm{A}^{*}$ & $\mathrm{~A}^{*+1}$ & $\mathrm{~N}^{* *}$ \\
$\boldsymbol{R}_{\boldsymbol{R}, \boldsymbol{y}}$ & 0 & $R_{o}$ & $R_{o}$ & $R_{o}$ \\
$\boldsymbol{O} \& \boldsymbol{M}_{\boldsymbol{R}, \boldsymbol{y}}$ & 0 & $O \& M_{0}$ & $R_{o}$ & $O \& M_{0}$ & $O \& M_{0}$ \\
$\boldsymbol{D} \boldsymbol{A}_{\boldsymbol{R}, \boldsymbol{y}}$ & 0 & $D A_{1}(1+i)^{-1}$ & $D \& M_{0}$ & 0 & 0 \\
$\boldsymbol{C A P P E \boldsymbol { X } _ { \boldsymbol { R } , \boldsymbol { y } }}$ & $C$ & 0 & $D A_{A}(1+i)^{-A}$ & 0 & $S V$ \\
$\boldsymbol{F C F F}_{\boldsymbol{R}, \boldsymbol{y}}$ & $-C$ & $\left(R_{0}-O \& M_{0}-D A_{1}(1+i)^{-1}\right)$ & $\left(R_{0}-O \& M_{0}-D A_{A}(1+i)^{-A}\right)$ & $\left(R_{0}-O \& M_{0}\right)$ & $\left(R_{0}-O \& M_{0}\right)$ \\
& & $(1-\operatorname{tax})+D A_{1}(1+i)^{-1}$ & $(1-\operatorname{tax})+D A_{A}(1+i)^{-A}$ & $(1-\operatorname{tax})$ & $(1-\operatorname{tax})+S V(1+i)^{-N}$
\end{tabular}

*A: number of years of amortization of the project

$* * \mathrm{~N}$ : total lifetime of the project

Table 4: Comparison between nominal and real discounted FCFF

\begin{tabular}{ccc}
\hline Year & $\boldsymbol{F C F F}_{\boldsymbol{R}, \boldsymbol{y}}$ & $\boldsymbol{F C F \boldsymbol { F } _ { \boldsymbol { N } , \boldsymbol { y } }}$ \\
\hline 0 & $-C$ & $-C$ \\
$1, \ldots$ & $\left(R_{0}-O \& M_{0}\right)(1-\operatorname{tax})+D A_{1}(1+i)^{-1} \operatorname{tax}$ & $\left(R_{o}-O \& M_{0}\right)(1+i)(1-\operatorname{tax})+D A_{1} \operatorname{tax}$ \\
$\ldots, \mathrm{A}^{*}$ & $\left(R_{0}-O \& M_{0}\right)(1-\operatorname{tax})+D A_{A}(1+i)^{-A} \operatorname{tax}$ & $\left(R_{o}-O \& M_{0}\right)(1+i)^{A}(1-\operatorname{tax})+D A_{A} \operatorname{tax}$ \\
$\mathrm{A}+1$ & $\left(R_{0}-O \& M_{0}\right)(1-\operatorname{tax})$ & $\left(R_{o}-O \& M_{0}\right)(1+i)^{A+1}\left(1-\operatorname{tax}_{y}\right)$ \\
$\mathrm{N}^{* *}$ & $\left(R_{0}-O \& M_{0}\right)(1-\operatorname{tax})+S V(1+i)^{-N}$ & $\left(R_{o}-O \& M_{0}\right)(1+i)^{N}\left(1-\operatorname{tax}_{y}\right)+S V$
\end{tabular}

*A: number of years of amortization of the project

$* * \mathrm{~N}$ : total lifetime of the project

\subsubsection{Investment Analysis Based on the FCFF}

After determining the FCFF it is possible to compute the IRR of the company investments. Looking to the IRR for FCFF for the whole life of a company is equivalent to computing the average Return On Assets (ROA) over the whole lifetime of the company.

In the following a list of the information that are needed to perform investment analysis based on the FCFF and a short evaluation of their availability:

- FCF, this information is internal to the investment and is not influenced by the environment where the company is set up;

- Tax rate, this information is derived from the company environment but is relatively steady;

- Inflation rate, this value is more volatile and more difficult to assess, but in terms of the real cash flow analysis, it tends to have low impact;

- Amortization timeline and amount.

The discounted free cash flow to firm, in real terms, is therefore:

$$
N P V_{F C F}=D F C F F=\sum_{y=0}^{N} \frac{F C F F_{R, y}}{\left(1+r_{R}\right)^{y}}
$$

The real IRR seen by the firm $\left(I R R_{F, R}\right)$ can be obtained by: 


$$
\sum_{y=0}^{N} \frac{F C F F_{R, y}}{\left(1+I R R_{F, R}\right)^{y}}=0
$$

The question is now what number the $I R R_{F, R}$ should be compared to. Since this is the cash flow seen by the company, it should be compared with the company cost of financing. The cost of financing seen by the company will be the weighted cost of equity and cost of debt (considering the tax recovery), where the weighting is the fraction of financing, respectively, by debt and by equity. In finance this is called the Weighted Average Cost of Capital (WACC). Of course it is possible to define both a real and nominal WACC:

$$
\begin{aligned}
W A C C_{N} & =\frac{C-E}{C}(1-\operatorname{tax}) r_{N, D}+\frac{E}{C} r_{N, E} \\
W A C C_{R} & =\frac{C-E}{C}(1-\operatorname{tax}) r_{R, D}+\frac{E}{C} r_{R, E}
\end{aligned}
$$

Where:

$C$ : Capital

$E$ : Equity

$r_{R, D}, r_{N, D}$ : respectively, real and nominal cost of debt, related by the real to nominal interest rate relationship described in Eq. 8, or in first approximation $r_{R, D}=r_{N, D}-i$, that is mostly equivalent to the interest paid on issued bond

$r_{R, E}, r_{N, E}$ : respectively, real and nominal cost of equity, related by the real to nominal interest rate relationship described in Eq. 8, or in first approximation $r_{R, E}=r_{N, E}-i$, that is mostly equivalent to the rate of return on the equity demanded by the market for similar investments.

The IRR test for the investment is passed if:

$$
I R R_{C, R}>W A C C_{R}
$$

For it has been said so far, the $W A C C_{R}$ is also the right discounting factor for the computation of the $N P V_{F C F}$ :

$$
N P V_{F C F F}=\sum_{y=0}^{N} \frac{F C F F_{R, y}}{\left(1+W A C C_{R}\right)^{y}}
$$

The calculation of the $N P V_{F C F}$ or the $W A C C_{R}$ require, in addition to the $I R R_{C, R}$, the knowledge of the internal capital structure of the company, the cost of debt and the cost of equity, so to determine the WACC. These are really specific characteristics of each company and, therefore, are of a lower value to the overall analysis for a general approach. Most of the financial offices provide for managers performing investment choices quarterly values for the WACC; hence, the calculation of the $N P V_{F C F}$ should probably be left to each company while the $I R R_{C, R}$ is still a meaningful quantity. But might be, if possible that the most relevant information is the yearly cash flow $F C F F_{R, y}$. 


\subsubsection{The Shareholder Case}

The investors, to evaluate the possible profit they could make out of the company, use free Cash Flow to Equity (FCFE). With respect the $F C F E_{y}$ it needs to be removed the stream of cash used to pay back the debt:

$$
F C F E_{y}=F C F F_{y}-I_{y}(1-\operatorname{tax})+N B_{y}
$$

where:

$I_{y}:$ Interest on debt

$N B_{y}$ : Net Borrowing

More detail, when this analysis is done with respect one single investment it is reasonable to assume that there is no bond emission but the only debt is represented by the initial loan to finance the project, in such a case:

$$
\begin{aligned}
& F C F E_{y}=F C F F_{y}-I_{y}(1-\operatorname{tax})+N B_{y} \\
& I_{y, N}=r_{N, D} R D_{y}=r_{N, D}\left(D_{0}-\sum_{y^{\prime}=1}^{y-1} L P_{y^{\prime}}\right) \\
& I_{y, R}=r_{N, D} R D_{y}(1+i)^{-y}=r_{N, D}(1+i)^{-y}\left(D_{0}-\sum_{y^{\prime}=1}^{y-1} L P_{y^{\prime}}\right) \\
& N B_{N, y}=\left\{\begin{array}{rc}
D_{0}, & y=0 \\
-L P_{N, y}, & 0<y \leq A \\
0, & A<y \leq N
\end{array}\right. \\
& N B_{R, y}=\left\{\begin{array}{cc}
D_{0}, \quad y=0 & \\
-L P_{R, y}=-L P_{N, y}(1+i)^{-y}, & 0<y \leq A \\
0, \quad A<y \leq N &
\end{array}\right.
\end{aligned}
$$

Where:

$L P_{y}$ : Loan Principal (yearly payback for the loan on the principal)

$r_{R, D}, r_{N, D}$ : respectively real and nominal cost of debt, related by the real to nominal interest rate relationship described in Eq. 8, or in first approximation $\left(r_{R, D}=r_{N, D}-i\right)$

$D_{0}$ : initial debt

It is useful to notice that:

$$
\left(\text { Debt }\left(D_{0}\right)+\text { Equity }\left(E_{0}\right)=\text { Capital to build }(C) \text { or Overnight Cost }\right)
$$


Table 5 depicts the comparative analysis between nominal and real values of FCFE.

Table 5: Comparison between nominal and real discounted FCFE

\begin{tabular}{ccc}
\hline Year & $\boldsymbol{F C F \boldsymbol { E } _ { R , y }}$ & $\boldsymbol{F C F \boldsymbol { E } _ { N , \boldsymbol { y } }}$ \\
\hline 0 & $-C+D_{0}$ & $-C+D_{0}$ \\
1 & $\left(R_{0}-O \& M_{0}\right)(1-\operatorname{tax})+D A_{1}(1+i)^{-1} \operatorname{tax}-$ & $\left(R_{o}-O \& M_{0}\right)(1+i)(1-\operatorname{tax})+D A_{1} \operatorname{tax}-$ \\
$D_{0} r_{N, D}(1+i)^{-1}(1-\operatorname{tax})-L P_{N, y}(1+i)^{-1}$ & $D_{0} r_{N, D}(1-\operatorname{tax})-L P_{N, y}$ \\
& $\left(R_{0}-O \& M_{0}\right)(1-\operatorname{tax})+D A_{A}(1+i)^{-A} \operatorname{tax}-$ & $\left(R_{o}-O \& M_{0}\right)(1+i)^{A}(1-\operatorname{tax})+D A_{A} \operatorname{tax}-$ \\
$\mathrm{A}$ & $-\left(D_{0}-\sum_{y \prime=1}^{A-1} L P_{y^{\prime}}\right) r_{N, D}(1+i)^{-A}(1-\operatorname{tax})$ & $-\left(D_{0}-\sum_{y \prime=1}^{A-1} L P_{y^{\prime}}\right) r_{N, D}(1-\operatorname{tax})-L P_{N, A}$ \\
& $-L P_{N, A}(1+i)^{-A}$ & $\left(R_{o}-O \& M_{0}\right)(1+i)^{A+1}(1-\operatorname{tax})$ \\
$\mathrm{A}+1$ & $\left(R_{0}-O \& M_{0}\right)(1-\operatorname{tax})$ & $\left(R_{o}-O \& M_{0}\right)(1+i)^{N}(1-\operatorname{tax})+S V$ \\
$\mathrm{~N}$ & $\left(R_{0}-O \& M_{0}\right)(1-\operatorname{tax})+S V(1+i)^{-N}$ &
\end{tabular}

\subsubsection{Investment Analysis Based on the FCFE}

If the analysis needs to be carried out from the point of view of the investors it is necessary to discount the cash flow as seen by the investor (FCFE). As was done for the previous analysis, we first compute the FCFE based on the real internal rate of return of the equity $\left(I R R_{E, R}\right)$ :

$$
\sum_{y=0}^{N} \frac{F C F E_{R, y}}{\left(1+I R R_{E, R}\right)^{y}}=0
$$

As in the case of the $I R R_{F, R}$, we ask what value this should be compared to. The right choice for this $I R R_{E, R}$ is the rate of return on equity that the market requires for similar equity. So the investment is acceptable if:

$$
I R R_{E, R}>r_{R, E}
$$

Eq. 52

Once we have assessed the right discounting factor it is possible to compute the right value of the NPV:

$$
N P V_{F C F E}=\sum_{y=0}^{N} \frac{F C F E_{R, y}}{\left(1+r_{R, E}\right)^{y}}
$$




\section{REFERENCES}

Bejan A., G. Tsaisaronis, M. Moran, 1996, Thermal Design and Optimization, New York: Wiley.

Bernstein M. A., J. Griffin, 2006, Regional Differences in the Price-Elasticity of Demand for Energy, National Renewable Energy Laboratory, NREL/SR-620-39512, February 2006.

Celasun O., G. Di Bella, T. Mahedy, C.Papageorgiou, 2014, “The U.S. Manufactoring Recovery: Uptick or Renaissance?" International Monetary Fund Working Paper, Western Hemisphere Department. International Monetary Fund.

DeVries, L. J., "The Instability of Competitive Energy-Only Electricity Markets," Research Symposium European Electricity Market, The Hague, Netherlands, September 2003.

Eldenburg, L. G., and S. K., Wolcott, 2005, Cost Management. Hoboken, NJ: John Wiley \& Sons, Inc.

Higgins, R. C., 2009, Analysis for Financial Management - 9th Edition, McGraw Hill Higher Education.

Joskow, P. L., 2006, Competitive Electricity Markets and Invenstment in New Generating Capacity, MIT Center for Energy and Environmental Research, Boston: Center for Energy and Environmental Research, June 12, 2006.

Madaeni S. H., R. Sioshansi, 2012, Comparison of Capacity Value Methods for Photovoltaics in the Western United States, National Renewable Energy Laboratory, NREL/TP-6A20-54704, July 2012.

Milligan M., K. Porter, 2008, Determining the Capacity Value of Wind: An Updated Survey of Methods and Implementation, National Renewable Energy Laboratory, NREL/CP-500-43433, June 2008.

Neri, M., D. Luscietti, M. Pilotelli, 2013, "Computing the Exergy of Solar Radiation from Real Radiation Data on the Italian Area," 12th Joint European Thermodynamics Conference, Brescia, Italy, July 1-5, 2013.

North American Electric Reliability Corporation, 2013, Summer 2013 Reliability Assessment, Atlanta: North American Electric Reliability Corporation, May 2013.

North American Electric Reliability Corporation, "Planning Reserve Margin," http://www.nerc.com/pa/RAPA/ri/Pages/PlanningReserveMargin.aspx, Web page visited August 28, 2014.

Querol E., B. Gonzalez-Regueral, L. Perez, 2013, Practical Approach to Exergy and Thermoeconomic Analyses of Industrial Processes, London: SpringerBriefs in Energy, pp. 9-28.

Szargut, J., 1980, “International progress in second law analysis," Energy, Vol. 5, No. 8-9, AugustSeptember 1980, pp. 709-718.

Valero A., L. Serra. J. Uche, 2006, "Fundamentals of Exergy Cost Accounting and Thermoeconomics, Part I: Theory," Journal of Energy Resources Technology, Vol. 128 (1), pp. 1-8.

Valero A., C. C., 2009, “Thermoeconomic Analysis,” Encyclopedia of Life Support Systems, Vol. Exergy, Energy System Analysis, and Optimization, Oxford, United Kingdom: EOLSS Publishers, pp. 347370.

Rant, Z. "Exergy, a new word for technical available work," Forschung auf dem Gebiete des Ingenieurwesens (in German), Vol. 22, 1956, pp. 36-37. 